Article

\title{
Impact of Cross-Linking of Collagen Matrices on Tissue Regeneration in a Rabbit Calvarial Bone Defect
}

\author{
Masako Fujioka-Kobayashi ${ }^{1,2}$, Elena Andrejova ${ }^{1}$, Hiroki Katagiri ${ }^{1,3}{ }^{(D}$, Benoit Schaller ${ }^{1}$, Anton Sculean ${ }^{4}{ }^{\circledR}$, \\ Jean-Claude Imber ${ }^{4} \mathbb{D}$, Niklaus P. Lang ${ }^{1}$ and Nikola Saulacic ${ }^{1, * \mathbb{D}}$ \\ 1 Department of Cranio-Maxillofacial Surgery, Inselspital, Bern University Hospital, University of Bern, \\ 3012 Bern, Switzerland; masako.kobayashi@tky.ndu.ac.jp (M.F.-K.); \\ elena.andrejova@students.unibe.ch (E.A.); katagiri@ngt.ndu.ac.jp (H.K.); benoit.schaller@insel.ch (B.S.); \\ nplang@switzerland.net (N.P.L.) \\ 2 Department of Oral and Maxillofacial Surgery, School of Life Dentistry at Tokyo, The Nippon Dental \\ University, Tokyo 102-8275, Japan \\ 3 Advanced Research Center, School of Life Dentistry at Niigata, The Nippon Dental University, \\ Niigata 951-8580, Japan \\ 4 Department of Periodontology, University of Bern, 3012 Bern, Switzerland; \\ anton.sculean@zmk.unibe.ch (A.S.); jean-claude.imber@zmk.unibe.ch (J.-C.I.) \\ * Correspondence: nikola.saulacic@insel.ch; Tel.: +41-31-632-87-64
}

check for updates

Citation: Fujioka-Kobayashi, M.; Andrejova, E.; Katagiri, H.; Schaller, B.; Sculean, A.; Imber, J.-C.; Lang, N.P.; Saulacic, N. Impact of Cross-Linking of Collagen Matrices on Tissue Regeneration in a Rabbit Calvarial Bone Defect. Materials 2021, 14, 3740. https://doi.org/10.3390/ ma14133740

Academic Editor: Steven J. Eppell

Received: 22 May 2021

Accepted: 2 July 2021

Published: 4 July 2021

Publisher's Note: MDPI stays neutral with regard to jurisdictional claims in published maps and institutional affiliations.

Copyright: (C) 2021 by the authors. Licensee MDPI, Basel, Switzerland. This article is an open access article distributed under the terms and conditions of the Creative Commons Attribution (CC BY) license (https:/ / creativecommons.org/licenses/by/ $4.0 /)$.

\begin{abstract}
The cross-linking of collagen matrices (Cl_CM) may provide volume-stable enhanced defect regeneration when compared to non-cross-linked matrices (Ncl_CM). The aim of the present study was to investigate the bone forming potential of collagen matrices (CMs) and the effects of cross-linking CMs in a rabbit calvaria defect model. (1) Empty controls $(n=6),(2)$ Ncl_CM $(n=8)$, and (3) Cl_CM $(n=8)$ were selected to be observed for the healing in $10 \mathrm{~mm}$ critical-sized calvarial bone defects. The potential for the bone as well as the connective tissue formation were evaluated by micro-CT and histomorphometry at three months post-surgery. There were no statistically significant differences in terms of new bone volume in the defects between the groups. However, the Cl_CM induced significantly greater fibrous tissue regeneration $\left(5.29 \pm 1.57 \mathrm{~mm}^{2}\right)$ when compared to the controls $\left(3.51 \pm 0.93 \mathrm{~mm}^{2}\right)$ by histomorphometry. The remnants of collagen fibers with immune cells, including macrophages and giant cells, were occasionally observed in the $\mathrm{Cl}$-CM group but not in the Ncl_CM group. In conclusion, the cross-linking of collagen did not influence the potential for bone formation. Nevertheless, Cl_CM might be advantageous for the maintenance of fibrous tissue volume without disturbing bone formation in the defects.
\end{abstract}

Keywords: collagen; cross-linking; tissue augmentation; bone formation

\section{Introduction}

Collagen matrices (CM) are routinely used as biomaterials to enhance wound healing and the regeneration of soft and hard tissue defects. In the dental field, a xenogeneic $\mathrm{CM}$ was recently developed for soft tissue augmentation and proved to be a suitable alternative to autogenous tissue transplants, maintaining tissue volume and thickness generally without adverse events such as infection [1-5]. Cross-linked CM (Cl_CM) has been developed for the improvement and lower shrinkage rate of non-cross-linked CM (Ncl_CM) [1,3]. The slower degradation of Cl_CM appeared to improve tissue volume stability for the long-term [1,6-8].

One of the disadvantages of the Cl_CM, however, is related to its lower biocompatibility when compared to Ncl_CM. For instance, it was reported that the glutaraldehyde cross-linked collagen membranes demonstrated lower cell attachment and viability when compared to non-cross-linked collagen membranes in human gingival fibroblasts [9]. Nevertheless, our previous in vitro study proved the excellent cytocompatibility of the chemically cross-linked Cl_CM as well as Ncl_CM on human THP-1-derived macrophages 
and gingival fibroblasts [10]. However, slight immune cell responses were observed with the higher mRNA levels of M1 markers, including interleukin (IL)-1 and IL-6, in the macrophages cultured on Cl_CM [10]. These data are in line with a recent publication reporting an early, slight inflammation after the implantation of bovine cross-linked collagen hemostats in Balb/c mice [11]. The biocompatibility of Cl_CM has also been documented in vivo, with obvious favorable soft and connective tissue integration and an adequate promotion of angiogenesis [1,3,12-16]. It was reported that soft tissue volume augmentation was obtained to a similar extent using Cl_CM and connective tissue graft (CTG) in preclinical and clinical studies [1,3]. For instance, Thoma et al. compared Cl_CM and CTG for their use in alveolar ridge augmentation around dental implants in dogs, which showed similar outcomes of soft tissue volume augmentation at the implant sites with minimal inflammatory reactions between two procedures for up to two months [1].

It is worth noting that collagen materials have been recognized to not only promote soft tissue regeneration but also support hard tissue regeneration, i.e., bone. Ncl_CMs are used for alveolar ridge preservation in order to maintain alveolar bone height and width after tooth extraction. It has recently been shown that a Cl_CM improved periodontal tissue regeneration when compared to an empty control in a two-wall intrabony defect model in dogs [17]. Additionally, it has been suggested that $\mathrm{Cl}$ _CM may be useful for soft tissue augmentation even in conjunction with guided bone regeneration (GBR) procedures [18]. As volume maintenance is essential for ridge preservation, a cross-linked volume-stable $\mathrm{CM}$ may serve this purpose better as opposed to non-cross-linked CMs. However, as $\mathrm{Cl} \_\mathrm{CMs}$ have primarily been developed for soft tissue augmentation, the effects of $\mathrm{Cl}$ _CM on bone formation in a critical-sized bone defect has not yet been investigated.

The aim of this study was to elucidate the bone forming potential of two collagen matrices in the form of sponges-one cross-linked (Cl_CM) and the other, non-cross-linked (Ncl_CM) - as compared to blood clot alone. Hence, these two types of CMs were tested in a critical-size bone defect at three months post-implantation by means of micro-CT and histological analysis, and were subsequently compared to an empty defect.

\section{Materials and Methods}

\subsection{Materials}

Two compositions of CMs were kindly provided by Geistlich Pharma AG, Wolhusen, Switzerland. Both consisted of collagen type I and III; one of them was non-cross-linked (Ncl_CM) and the other was chemically cross-linked (Cl_CM). Both CMs were porous, resorbable biomaterials, specifically designed for soft-tissue augmentation. The CMs were morphologically observed via scanning electron microscopy (SEM) (DSM 982, Zeiss, Oberkochen, Germany) (Figure 1). Both Ncl_CM and Cl_CM showed three-dimensional (3D) mesh patterns at low magnification, whereas $\mathrm{Cl}$-CM further included relatively dense structures of collagen fibers at high magnification.

\subsection{Animals}

Twelve New Zealand White female rabbits, approximately 16 weeks of age (2.6-3.4 kg), were used in the present study. The sample size of animals (sham: 8 rabbits, Ncl_CM: 8 rabbits, and $\mathrm{Cl}$ CM: 8 rabbits) were estimated by using G*power [19]. Unfortunately, due to the unexpected death of an animal after surgery, the total sample number of 22 was used for the evaluation instead.

The present study was approved by the Committee for Animal Research, Canton of Bern, Switzerland (Nr: BE 89/17). The NC3Rs, UK guidelines, and ARRIVE guidelines for preclinical in vivo studies were considered. After the acclimatization period, the animals were housed without excessive or disturbing noises, fed a standard diet, and given water ad libitum. 

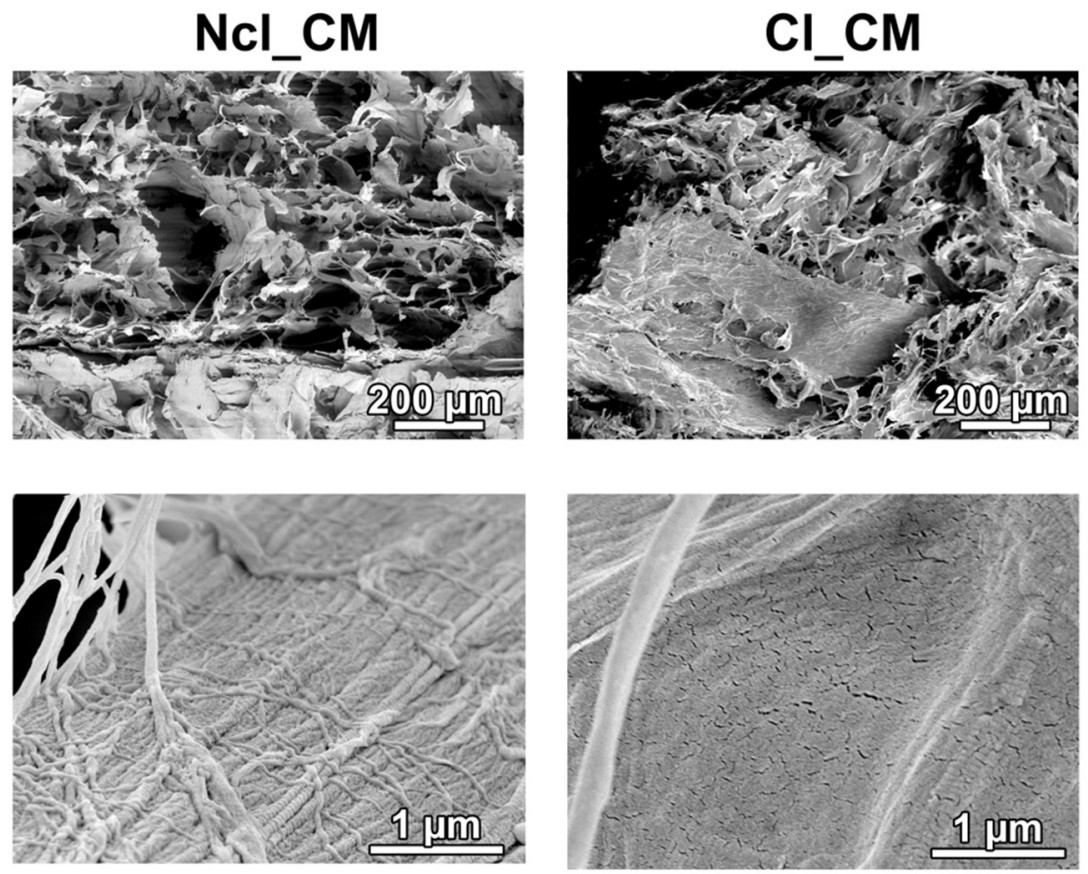

Figure 1. SEM images of the non-cross-linked collagen matrix (Ncl_CM) and cross-linked CM $\left(\mathrm{Cl} \_\mathrm{CM}\right)$ at low magnification $(100 \times)$ and high magnification $(30,000 \times)$.

\subsection{Anesthesia}

Anesthesia was performed, as previously reported [20]. Briefly, the animals were premedicated subcutaneously (s.c.) with methadone $(0.3 \mathrm{mg} / \mathrm{kg})$ and dexmedetomidine $(100 \mathrm{~g} / \mathrm{kg})$ mixed with ketamine $(15 \mathrm{mg} / \mathrm{kg})$. General anesthesia was maintained with isoflurane vaporized in pure oxygen through a Jackson Rees modified T-piece breathing system, targeting a maximal Et Iso of $1-1.3 \%$. Ropivacaine $0.75 \%$ was locally administered on the surgical site.

\subsection{Surgical Procedures}

The skin of the head was incised from the nasal bone to the mid-sagittal crest, and the parietal bone was exposed after the periosteum elevation. Two critical-sized $(10 \mathrm{~mm}$ diameter) bone defects were prepared in the parietal bones with a trephine drill, with maximal care not to injure the dura mater. Both CM biomaterials were pre-shaped with a scalpel into $10 \mathrm{~mm}$ diameter and $3 \mathrm{~mm}$ thickness cylinder (Figure 2A), and implanted in the defects without excessive pressure (Figure 2B). The applied treatment modalities, (1) empty control $(n=6),(2)$ Ncl_CM $(n=8)$, and (3) Cl_CM $(n=8)$, were randomly allocated. The wound was sutured in two layers using 4-0 Vicryl ${ }^{\circledR}$ (Ethicon, Somerville, NJ, USA) and 4-0 Monocryl ${ }^{\circledR}$ sutures (Ethicon). Furthermore, the surfaces of the wound were covered with a spray film dressing (OPSITE ${ }^{\circledR}$ SPRAY, Smith \& Nephew, London, UK). 
A

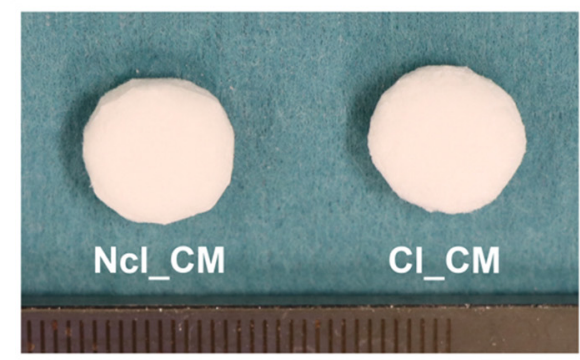

B

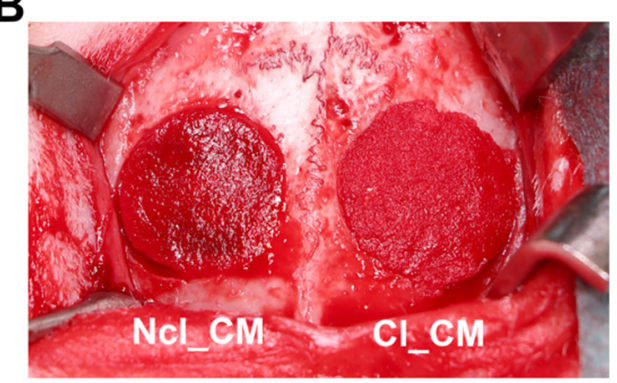

Figure 2. (A) Pre-shaped Ncl_CM (left) and Cl_CM (right) before the implantation ( $\varphi=10 \mathrm{~mm}$, thickness $=3 \mathrm{~mm}$ ). (B) Image of the implanted CMs during surgery.

\subsection{Postoperative Procedures}

Perioperatively, antimicrobial prophylaxis (procaine penicillin 150,000 IU / $\mathrm{mL}+$ benzathine penicillin 150,000 IU/mL; $0.01 \mathrm{~mL} / \mathrm{kg}$ s.c, Duplocillin ${ }^{\circledR}$, MSD Animal Health, Luzern, Switzerland) were applied. As postoperative analgesia, meloxicam (Metacam ${ }^{\circledR}$, Boehringer Ingelheim, Ingelheim, Germany) $0.5 \mathrm{mg} / \mathrm{kg}$ s.c., once daily during postoperative period of 4 days, and buprenorphine (Temgesic ${ }^{\circledR}$, Rechitt Benckiser, Wallisellen, Switzerland) $20 \mathrm{~g} / \mathrm{kg}$ s.c., every $8 \mathrm{~h}$ during postoperative period of 3 days were administered. The animals were euthanized at 3 months post-surgery with an overdose of pentobarbital $120 \mathrm{mg} / \mathrm{kg}$ i.v., after the premedication with ketamine $65 \mathrm{mg} / \mathrm{kg}$ and xylazine $4 \mathrm{mg} / \mathrm{kg}$ s.c.

\subsection{Micro-CT Analysis}

The collected calvarial samples were fixed in a 10\% neutral formalin solution for 7 days at room temperature and kept in $70 \%$ ethanol at $4{ }^{\circ} \mathrm{C}$. The micro-CT scans were performed by utilizing a desktop cone beam scanner (micro-CT 40, ScancoMedical AG, Brüttisellen, Switzerland). The micro-CT DICOM images (voxel size; $18 \mu \mathrm{m}$ ) were then analyzed and 3D reconstructed by a software (Amira ver. 2019, Thermo Fischer Scientific, Waltham, MA, USA). The volume of interest (VOI) was set as $10 \mathrm{~mm}$ diameter, full thickness cylinders, selected corresponding to the dimensions of the bone defect sites. Two-dimensional parameters included the defect closure measured on the horizontal plane (DC, relative $\%$ to whole defect length; $10 \mathrm{~mm}$ ) and bone height $(\mathrm{BH})$ measured on the sagittal plane, in the middle $5 \mathrm{~mm}$ (BH middle) and the lateral part of the defect (BH lateral). Threedimensional parameters including bone volume $\left(\mathrm{BV}, \mathrm{mm}^{3}\right)$, $\mathrm{BV}$ fraction $(\mathrm{BV} / \mathrm{TV}$, ratio of the segmented $\mathrm{BV}$ to the total tissue volume), and bone density $(\mathrm{BD}, \mathrm{mgHA} / \mathrm{ccm}$ at the defect site), were calculated.

\subsection{Histological Processing and Histomorphometric Analysis}

All calvarial samples were dehydrated in ascending concentrations of ethanol, and embedded in methyl methacrylate (MMA) without decalcification. For accurate bone histomorphometry, only the undecalcified sections were prepared in the present study. The MMA-embedded blocks were cut sagittally into $1000 \mu \mathrm{m}$ thick ground sections in the middle of the defects using a diamond saw (VC-50; LECO, St. Joseph, MI, USA). After mounting on acrylic glass slabs, the sections were ground and polished to a final thickness of $200 \mu \mathrm{m}$, then stained with toluidine blue and fuchsin. The images were captured under a digital microscope (VHX-6000, Keyence, Japan). Histomorphometry was performed by Photoshop CC software (Adobe, San Jose, CA, USA) in the region of interest (ROI 1) corresponding to $10 \mathrm{~mm}$ initial defect sites, as previously reported [20,21] (Figure 3). Linear parameters included horizontal defect closure (HDC, \%), new bone height in the middle $5 \mathrm{~mm}$ area (ROI 2; NBH middle, $\mathrm{mm}$ ), NBH in the lateral $5 \mathrm{~mm}$ area (ROI 3; $\mathrm{NBH}$ lateral, $\mathrm{mm}$ ), maximal connective tissue height (maximal CTH, $\mathrm{mm}$ ), maximal adipose tissue height (maximal ATH, mm), and maximal fibrous tissue height (maximal FTH, mm) were determined. Furthermore, as area parameters, new bone area $\left(\mathrm{NBA}, \mathrm{mm}^{2}\right)$, bone 
marrow area $\left(\mathrm{BMA}, \mathrm{mm}^{2}\right)$, residual material area $\left(\mathrm{RMA}, \mathrm{mm}^{2}\right)$, connective tissue area $\left(\mathrm{CTA}, \mathrm{mm}^{2}\right)$, adipose tissue area $\left(\mathrm{ATA}, \mathrm{mm}^{2}\right)$, and fibrous tissue area $\left(\mathrm{FTA}, \mathrm{mm}^{2}\right.$ ) were calculated in ROIs.

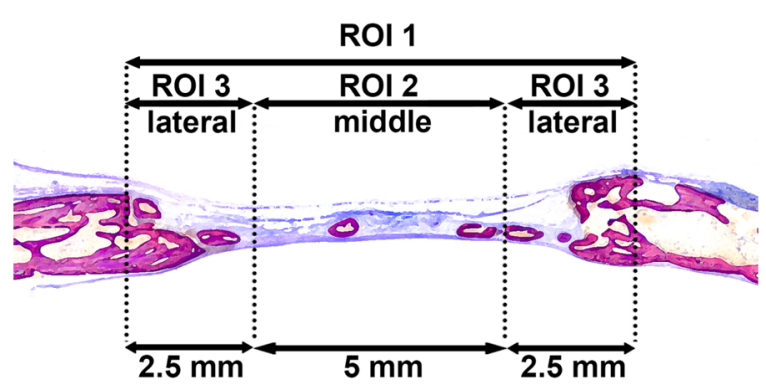

Figure 3. ROIs for histomorphometry. ROI 1 represents the whole defect area $(10 \mathrm{~mm})$, ROI 2 is middle area of the defect $(5 \mathrm{~mm})$, and ROI 3 is lateral area of the defect $(2.5 \mathrm{~mm}+2.5 \mathrm{~mm})$.

\subsection{Statistical Analysis}

The floating bars in the graphs represent the minimum and maximum values with the mean values for all quantitative data. The statistical analysis was performed using one-way analysis of variance (ANOVA) with Tukey test by a statistical software (GraphPad Prism 8.0; GraphPad Software, Inc., La Jolla, CA, USA). The $p$ values $<0.05$ were considered significant.

\section{Results}

\subsection{General Observation during and Post-Surgery}

During surgeries, dried Ncl_CM and Cl_CM placed into the defect were readily and completely soaked with the surrounding blood. Both materials as scaffolds of stable blood clot showed slight swelling in the defects; however, the periosteum and skin could be easily closed without major tension. In general, wound healing was uncomplicated, without signs of inflammation, infection, wound dehiscence or exposure of the surgical sites post-operatively.

\subsection{Micro-CT Analysis}

The specimens were first analyzed by micro-CT (Figure 4). All groups showed some new bone formation in the bone defects. However, none of the defects led to complete closure after three months. The control empty samples tended to induce smooth new bone islands in the defects, while Ncl_CM and Cl_CM samples demonstrated relatively rough new bone surfaces where the materials were implanted, usually connected to the initial peripheral bone edges (Figure 4A). There were no statistically significant differences in any quantifiable parameter among the three tested groups (Figure 4B). BV/TV in the control group, for example, demonstrated $20.96 \pm 5.47 \%$, while it was $19.23 \pm 3.08 \%$ in Ncl_CM and $17.63 \pm 4.46 \%$ in Cl_CM. The new bone tissue of the empty control group tended to grow toward the middle of the defect region, but the lateral area of bone looked relatively thin when compared to the defects filled with CMs. Both Ncl_CM and Cl_CM showed relatively thick new bone in the lateral area of the defects. However, new bone in middle area of the defects was rarely observed in both $\mathrm{Ncl}$-CM and $\mathrm{Cl}$ _CM groups. The Bone Density values revealed that the new bone at three months post-surgery was still immature (low mineral density) when compared to the reference bone (Figure 4B). 


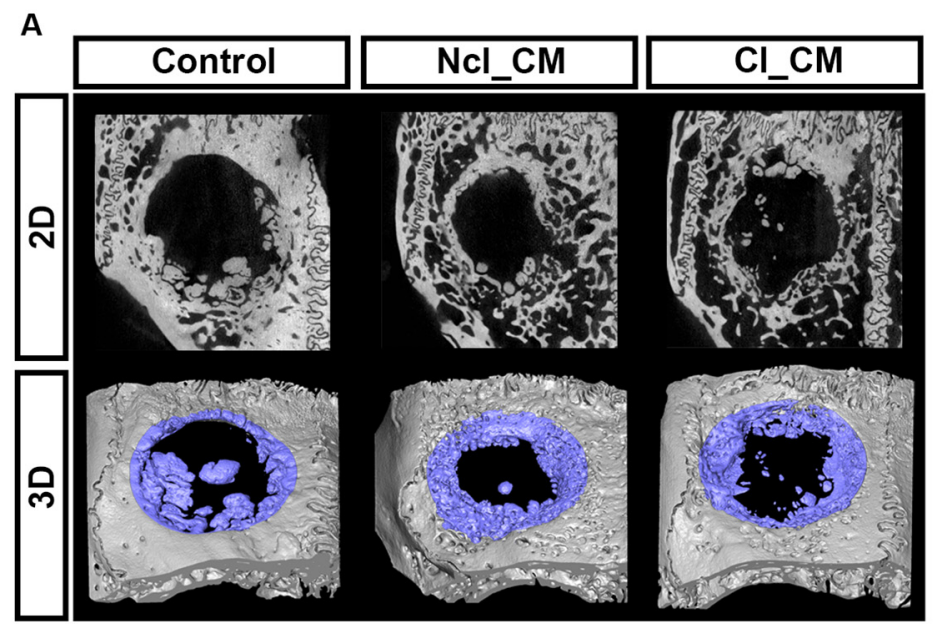

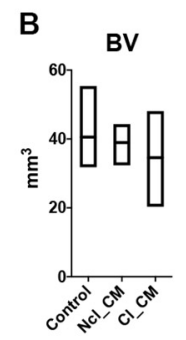
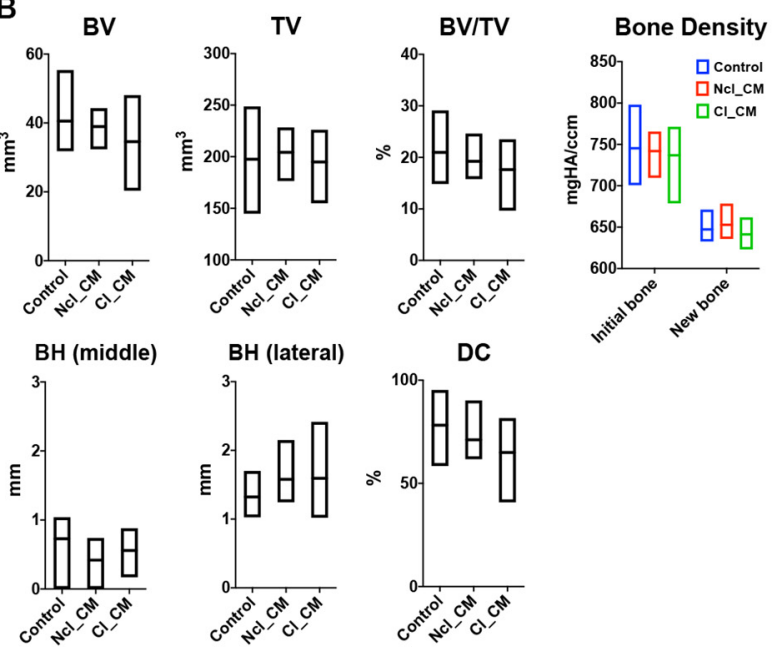

Figure 4. The micro-CT analysis. (A) Representative images of the micro-CT data in each group; the 2D plane (upper row) and 3D-reconstructed views (lower row; the blue color shows new bone in VOI). (B) The quantified data of the micro-CT analysis. Bone volume $\left(\mathrm{BV}, \mathrm{mm}^{3}\right)$, total volume $\left(\mathrm{TV}, \mathrm{mm}^{3}\right), \mathrm{BV} / \mathrm{TV}(\%)$, bone density $(\mathrm{mmHA} / \mathrm{ccm})$, bone height $(\mathrm{BH}, \mathrm{mm})$ in middle area, $\mathrm{BH}$ in lateral area, and defect closure (DC, \%) were calculated in each group at three months post-surgery. No significant differences were observed in any parameters among the tested groups.

\subsection{Histological Analysis}

Similar results were observed in the histological analysis as compared to the micro$\mathrm{CT}$ analysis (Figures 5-7). The new bone stretched out to the middle of the defects in the empty controls, whereas Cl_CM maintained thicker new bone in the peripheral area (Figure 5). Some residual materials remained, especially in the middle area in the Cl_CM group (Figure 5). No obvious residual materials were found in the Ncl_CM group. There were no statistically significant differences in NBA, BMA, RMA, CTA, and ATA (Figure 5B). However, a trend could be observed towards increased CTA and ATA at the expense of NBA and BMA in the case of the $\mathrm{CMs}$, with $\mathrm{Cl}_{-} \mathrm{CM}$ being more pronounced. Statistically significantly higher FTA was found in $\mathrm{Cl} \_\mathrm{CM}\left(5.29 \pm 1.57 \mathrm{~mm}^{2}\right)$ when compared to the empty controls $\left(3.51 \pm 0.93 \mathrm{~mm}^{2},{ }^{*} p=0.0337\right)$ (Figure $\left.5 \mathrm{~B}\right)$.

Similarly, in the middle of the defects, thicker fibrous tissue was observed in $\mathrm{Cl}$ _CM $(0.92 \pm 0.28 \mathrm{~mm})$ when compared with both empty controls $\left(0.62 \pm 0.18 \mathrm{~mm},{ }^{*} p=0.0367\right)$ and Ncl_CM $(0.68 \pm 0.15 \mathrm{~mm}, p=0.0849)$ (Figures 6 and 7$)$. No residual materials were observed for any of the Ncl_CM specimens. Lymphocytes were, however, occasionally detected in the connective tissue in the Ncl_CM group (Figure 6B). The remnants of $\mathrm{Cl}$ CCM were encapsulated in the connective tissue and accompanied by numerous lymphocytes and multinucleated giant cells (MNGCs) (Figure 6D). No statistically significant differences were observed in the linear parameters except for maximal FTH between the groups (Figure 7). 
A

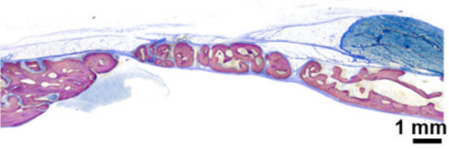

Ncl CM

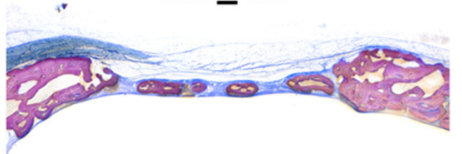

RMA

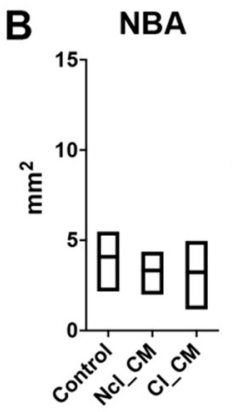

BMA
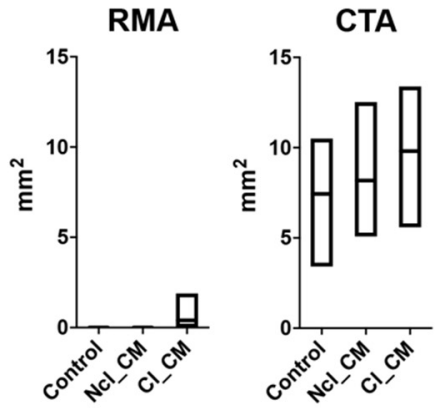

C

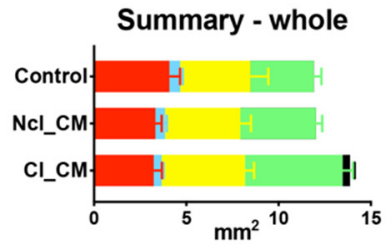

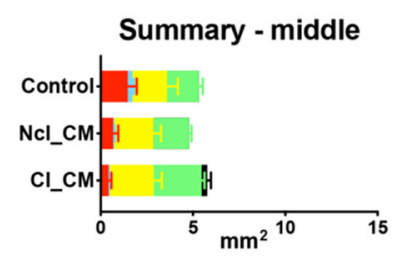

Cl_CM

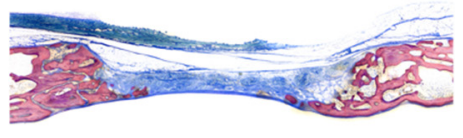

ATA
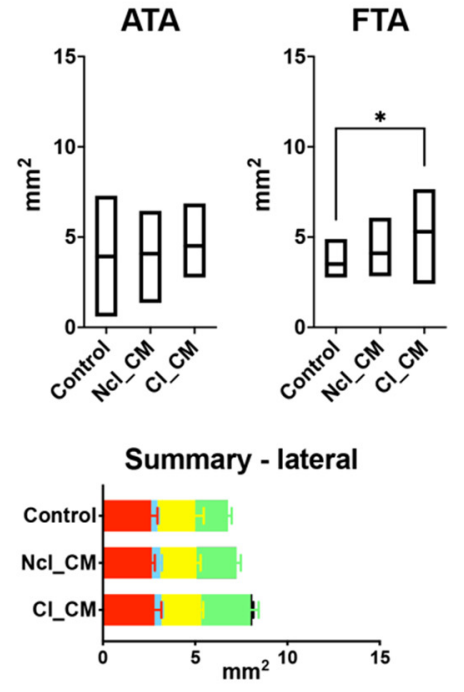

NBA BMA ATA FTA RMA

Figure 5. (A) Overviews of toluidine blue and fuchsin staining of the defect on the sagittal plane at three months postsurgery. (B) Histomorphometry of area parameters including new bone area (NBA, $\left.\mathrm{mm}^{2}\right)$, bone marrow area $\left(\mathrm{BMA}^{\mathrm{m}} \mathrm{m}^{2}\right)$, residual material area $\left(\mathrm{RMA}, \mathrm{mm}^{2}\right)$, connective tissue area $\left(\mathrm{CTA}, \mathrm{mm}^{2}\right)$, adipose tissue area $\left(\mathrm{ATA}, \mathrm{mm}^{2}\right)$, and fibrous tissue area $\left(\mathrm{FTA}, \mathrm{mm}^{2}\right) .{ }^{*}$ denotes significant difference between the groups; $p<0.05$. (C) Summary of area parameters in whole defects (ROI 1), middle area of the defects (ROI 2), and lateral area of the defects (ROI 3 ).
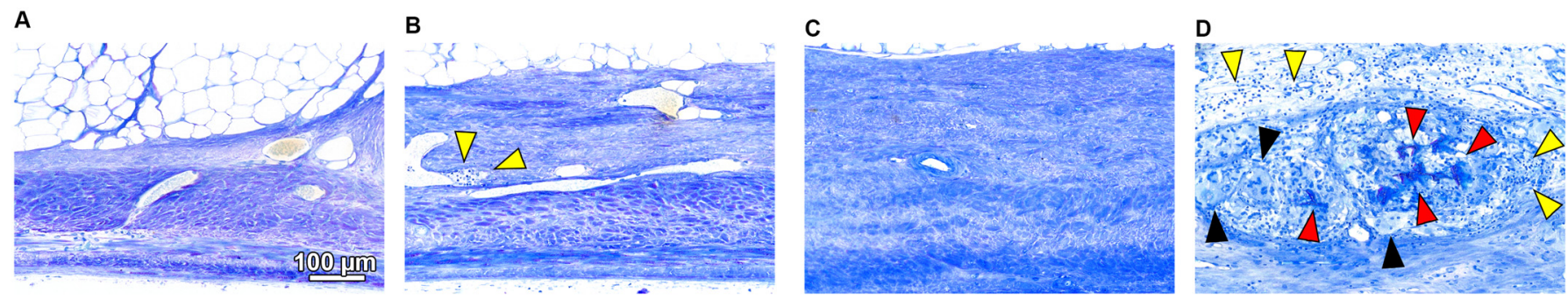

Figure 6. The magnified views of toluidine blue and fuchsin staining in the middle area at high magnification $(500 \times)$ in (A) Control (empty), (B) Ncl_CM, and (C,D) Cl_CM groups at three months post-surgery. The yellow arrowheads show lymphocytes, red arrowheads indicate residual materials, and black arrowheads show multinucleated giant cells (MNGCs).
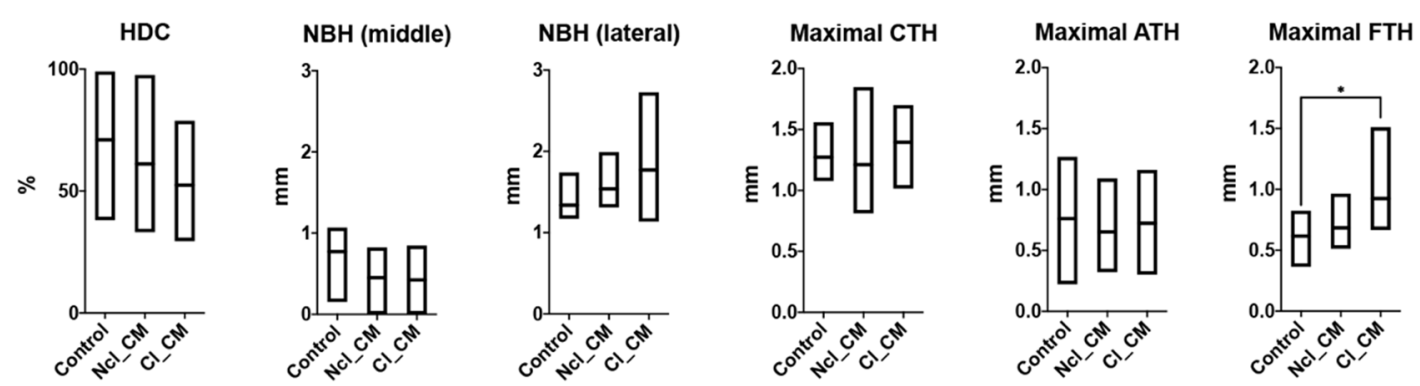

Figure 7. Histomorphometry of linear parameters including horizontal defect closure (HDC, \%), new bone height in the middle area (NBH middle, $\mathrm{mm}$ ), NBH in the lateral area (NBH lateral, $\mathrm{mm}$ ), maximal connective tissue height (Maximal $\mathrm{CTH}, \mathrm{mm}$ ), maximal adipose tissue height (Maximal ATH, mm), and maximal fibrous tissue height (Maximal FTH, mm) at three months post-surgery. ${ }^{*}$ denotes significant difference between the groups; $p<0.05$. 


\section{Discussion}

The present experimental study evaluated in a critical-sized defect model, the bone forming potential of two collagen matrices (Cl_CM; Ncl_CM) as compared with empty defects, and investigated the potential positive effects of the increased volume stability obtained through the chemical crosslinking of a CM. No statistically significant difference could be detected in terms of new bone formative potential between the two CMs and the empty defect in the whole defect. However, the obvious trend was that in the case of both collagen scaffold groups, less bone was formed especially in the middle area of the defect when compared to the empty defect group at three months after augmentation. This effect was more pronounced in the case of the cross-linked collagen $(\mathrm{Cl} / \mathrm{CM})$ when compared with the non-cross-linked collagen ( $\left.\mathrm{Ncl}_{-} \mathrm{CM}\right)$. Taken together, these findings indicate a delayed bone formation in the presence of CMs in the middle portion of the defect.

The Cl_CMs were previously introduced for soft tissue augmentation, as an alternative to autogenous soft tissue grafts, while the studies performed showed that the matrices may also provide space and preserve the tissue volume $[1,3]$. As volume maintenance is also essential for alveolar ridge preservation, it was hypothesized that $\mathrm{Cl} C \mathrm{CM}$ may serve the same purpose when placed into bony defects. Unfortunately, the overall bone formation was unaffected by the scaffolding with the cross-linking of CMs, if not even negatively impacted. Moreover, the analysis revealed that this negative trend was less evident in the case of Ncl_CM. Given that (i) Cl_CM is chemically cross-linked, (ii) chemical crosslinking is known to modulate the collagen binding region for $\alpha 2 \beta 1$ integrin [22], the latter functioning as primary platelet adhesion receptor [23], we assume less efficient blood clot formation as the potential cause for the observed trend, considering blood clot formation as the essential first step in bone formation.

Despite the observed delay in overall bone formation kinetics, it has to be emphasized that $\mathrm{Cl}$ _CM allowed for a horizontal and vertical ingrowth of new bone at the defect borders in contrast to the Ncl_CM and empty defects. This indicates that a non-cross-linked highly porous $\mathrm{CM}$, despite occupying the whole defect in the very early phase of bone healing, resorbs too early and cannot prevent the collapse of connective tissue into the defect site. In combination with a missing barrier, this leads to an outcome similar to an empty defect. A stable, highly porous collagen matrix may prevent the collapse of the surrounding tissue into the defect area. Clearly, the resorption kinetics of the tested Cl_CM in this study needs to be balanced to the bone formation, continuously maintaining the space for new bone. A functional barrier excluding fibrous tissue seems to be mandatory for successful bone augmentation, as significantly more fibrous tissue in the defect has been found when compared to Ncl_CM as well as empty defects.

The in vitro assay was not chosen in the present study to compare the Ncl_CM and $\mathrm{Cl} \_\mathrm{CM}$ for osteogenic potential. The effect of the different $\mathrm{Ncl} \_\mathrm{CM}$ and $\mathrm{Cl}$ _CMs on cell behavior in macrophages and gingival fibroblasts were previously investigated [10]. It was unfortunately revealed that the Ncl_CMs are resorbed in cell culture media within a couple of days, and this quick resorption process influenced cell viability. Therefore, an in vitro osteoblast differentiation assay was not performed as it requires long-term culture periods. However, it is interesting that the osteogenetic potential was reportedly promoted by bone marrow-derived multipotent stromal cells cultured on cross-linked collagen membranes in comparison to non-cross-linked collagen membranes, supported by higher alkaline phosphatase (ALP) expression, calcium deposition, and angiogenic potential [24]. A $10 \mathrm{~mm}$ critical-size defect in rabbit calvariae is one of the best established models to evaluate the bone regeneration potential of biomaterials [25] and was chosen for this study. The bone defect models of smaller animals could not be considered to evaluate the bone formation potential of the tested CMs because of the thickness of the materials, which are not membranes. There was, however, no obvious benefit of CM application, cross-linked or non-cross-linked, on the formation of new bone in the present in vivo study, as indicated by both micro-CT analysis and histomorphometry. Nevertheless, in our study, we did not use barrier membranes to exclude the ingrowth of soft tissue, as requested 
conceptually by the guided bone regeneration (GBR) approach. Thus, despite the absence of collagen barrier membranes, the used CMs performed as volume-stable scaffolds that occupied the entire bone defects. On the other hand, both CMs did not hinder the formation of new bone as compared to the empty controls. The present study, therefore, does not exclude the fact that the CMs may provide a positive impact on bone formation in less demanding defect models.

Despite the fact that the tested CMs did not influence bone formation, the present results supported findings from previous studies on soft tissue regeneration-both CMs were incorporated into the newly formed tissue without distinctive borders to the $\mathrm{CM}$ or encapsulation $[1,26]$. Interestingly, the $\mathrm{Cl}$-CMs yielded the highest CTA, ATA, and FTA among the modalities tested. In contrast to Ncl_CM, the difference of the results of $\mathrm{Cl}$-CM reached statistical significance for both FTA and FTH when compared to the empty control. Thus, modification of the degradation kinetics of CMs by chemical crosslinking and its influence on the formation of soft tissue has been confirmed. These findings further point to the necessity to exclude soft tissue ingrowth, in line with the guided bone regeneration concept.

In the present study, MNGCs and a mononuclear infiltrate were detected in the $\mathrm{Cl}$ CM samples around the remnants of the materials in the middle defect area. The mononuclear infiltration around collagen fiber remnants suggests an extended inflammation, the latter potentially driven by M1 macrophages causing a delay in tissue integration. In that respect, our data are in agreement with results reported for cross-linked collagen membranes [27]; the higher degree of cross-linking was found responsible for the prolonged periods of resorption of the remnants [28], stimulating in parallel pro-inflammatory reactions and the activation of macrophage colonies more than their non-cross-linked counterparts [29]. These findings have been confirmed in the in vivo analysis of bovine cross-linked collagen sponges, which caused a benign and transient immune reaction [11]. In contrast, non-crosslinked collagen membranes were completely degraded by collagenases exerting only a small inflammatory reaction, without a foreign body reaction [29]. The same complete resorption of Ncl_CM was also observed in the present study. In conclusion, the crosslinked as well as non-cross-linked collagen matrices display distinct biological behavior, corroborating earlier findings on the respective collagen membranes.

When implanted into the soft tissues, MNGCs expressing CD86, cathepsin K, and tartrate-resistant acid phosphatase (TRAP) were found to be responsible for the degradation of CMs [15]. Macrophages are known to regulate the vascularization [30] and the rapid synthesis of collagen fibrils [31]. Furthermore, neutrophils also contribute to inflammation, macrophage recruitment, M2 macrophage polarization, inflammation resolution, and angiogenesis during tissue regeneration following the implantation of the biomaterials in the body [32]. Ye et al. observed differences in the infiltration of neutrophils between two dermal sheep collagen membranes cross-linked by glutaraldehyde and hexamethylene diisocyanate in murine subcutaneous tissue [33]. It was demonstrated that neutrophils upregulated the expression of interferon (IFN)- $\gamma$, which activates macrophages [33]. However, comprehensive knowledge is lacking about the subsequent healing events, and the immuno-cells behavior in the pores of the CMs is not yet fully understood. An appropriate balance between the resorption speed of biomaterials and the degree of bone formation/replacement might be beneficial for bone regeneration, depending on each clinical situation [34]. The present study did not clarify the functions of the related immune cells and bone forming cells because of the limited observation periods and assay procedures. Further studies are therefore urged to fully understand the immuno-function of CM on tissue regeneration.

\section{Conclusions}

The present findings revealed that both collagen matrices, $\mathrm{Ncl}$ CCM and $\mathrm{Cl}_{-} \mathrm{CM}$, did not improve bone formation when compared to the sham control group for three months. 
However, the Cl_CM showed slow resorption promoting connective tissue augmentation, without significantly disturbing bone formation in critical-size calvaria defects in rabbits.

Author Contributions: Conceptualization, M.F.-K., B.S., E.A., H.K. and N.S.; investigation, M.F.-K., E.A., H.K., B.S., J.-C.I., and N.S.; methodology, M.F.-K., N.P.L., and N.S.; supervision, A.S. and N.P.L.; writing—original draft, M.F.-K. and N.S.; writing—review and editing, B.S., A.S., J.-C.I., and N.P.L. All authors have read and agreed to the published version of the manuscript.

Funding: The study was supported by Geistlich Pharma AG, Wolhusen, Switzerland and the Department of Cranio-Maxillofacial Surgery, Faculty of Medicine, University of Bern, Switzerland.

Institutional Review Board Statement: The study was conducted according to the guidelines of the Declaration of Helsinki, and approved by the Committee for Animal Research, Canton of Bern, Switzerland (Nr: BE 89/17).

Informed Consent Statement: Not applicable.

Data Availability Statement: Data sharing not applicable.

Acknowledgments: The authors wish to thank the staff at Experimental Surgery Facility (ESF) and Central Animal Facilities (CAF), Department of BioMedical Research (DBMR), University of Bern, Switzerland, for their support in the animal surgeries and management. We also thank Inga Grigaitiene for her support in micro-CT image taking, histological preparation, and histomorphometry; Mark Siegrist for his assistance in micro-CT data management; and Helga Maria Mogel-Allemann and Michael H. Stoffel for their assistance in SEM image observation. The tested collagen materials were kindly provided by Geistlich Pharma AG (Wolhusen, Switzerland).

Conflicts of Interest: The authors declare no conflict of interest.

\section{References}

1. Thoma, D.S.; Naenni, N.; Benic, G.I.; Hämmerle, C.H.; Jung, R.E. Soft tissue volume augmentation at dental implant sites using a volume stable three-dimensional collagen matrix-histological outcomes of a preclinical study. J. Clin. Periodontol. 2017, 44, 185-194. [CrossRef] [PubMed]

2. Herford, A.S.; Akin, L.; Cicciu, M.; Maiorana, C.; Boyne, P.J. Use of a porcine collagen matrix as an alternative to autogenous tissue for grafting oral soft tissue defects. J. Oral Maxillofac. Surg. 2010, 68, 1463-1470. [CrossRef] [PubMed]

3. Thoma, D.S.; Zeltner, M.; Hilbe, M.; Hämmerle, C.H.; Hüsler, J.; Jung, R.E. Randomized controlled clinical study evaluating effectiveness and safety of a volume-stable collagen matrix compared to autogenous connective tissue grafts for soft tissue augmentation at implant sites. J. Clin. Periodontol. 2016, 43, 874-885. [CrossRef]

4. Schmitt, C.M.; Matta, R.E.; Moest, T.; Humann, J.; Gammel, L.; Neukam, F.W.; Schlegel, K.A. Soft tissue volume alterations after connective tissue grafting at teeth: The subepithelial autologous connective tissue graft versus a porcine collagen matrix-A pre-clinical volumetric analysis. J. Clin. Periodontol. 2016, 43, 609-617. [CrossRef]

5. Schmitt, C.M.; Moest, T.; Lutz, R.; Wehrhan, F.; Neukam, F.W.; Schlegel, K.A. Long-term outcomes after vestibuloplasty with a porcine collagen matrix $\left(\right.$ Mucograft ${ }^{\circledR}$ ) versus the free gingival graft: A comparative prospective clinical trial. Clin. Oral Implants Res. 2016, 27, e125-e133. [CrossRef] [PubMed]

6. Herford, A.S.; Nguyen, K.; Miller, M.; Tandon, R.; Signorino, F. Evaluation of the Safety and Efficacy of Soft Tissue Augmentation With a Compressive-Resistant Collagen Matrix in a Nonhuman Primate Model. J. Oral Maxillofac. Surg. 2019, 77, 615-628. [CrossRef] [PubMed]

7. Huber, S.; Zeltner, M.; Hämmerle, C.H.; Jung, R.E.; Thoma, D.S. Non-interventional 1-year follow-up study of peri-implant soft tissues following previous soft tissue augmentation and crown insertion in single-tooth gaps. J. Clin. Periodontol. 2018, 45, 504-512. [CrossRef]

8. Rothamel, D.; Benner, M.; Fienitz, T.; Happe, A.; Kreppel, M.; Nickenig, H.-J.; Zöller, J.E. Biodegradation pattern and tissue integration of native and cross-linked porcine collagen soft tissue augmentation matrices-An experimental study in the rat. Head Face Med. 2014, 10, 10. [CrossRef]

9. Ardakani, M.R.T.; Hajizadeh, F.; Yadegari, Z. Comparison of attachment and proliferation of human gingival fibroblasts on different collagen membranes. Ann. Maxillofac. Surg. 2018, 8, 218.

10. Fujioka-Kobayashi, M.; Ülgür, I.I.; Katagiri, H.; Vuignier, S.; Schaller, B. In Vitro observation of macrophage polarization and gingival fibroblast behavior on three-dimensional xenogeneic collagen matrixes. J. Biomed. Mater. Res. Part A 2020, 108, 1408-1418. [CrossRef]

11. Zhang, L.; Niu, X.; Sun, L.; She, Z.; Tan, R.; Wang, W. Immune response of bovine sourced cross-linked collagen sponge for hemostasis. J. Biomater. Appl. 2018, 32, 920-931. [CrossRef]

12. Thoma, D.S.; Villar, C.C.; Cochran, D.L.; Hammerle, C.H.; Jung, R.E. Tissue integration of collagen-based matrices: An experimental study in mice. Clin. Oral Implant. Res. 2012, 23, 1333-1339. [CrossRef] 
13. Ferrantino, L.; Bosshardt, D.; Nevins, M.; Santoro, G.; Simion, M.; Kim, D. Tissue Integration of a Volume-Stable Collagen Matrix in an Experimental Soft Tissue Augmentation Model. Int. J. Periodontics Restor. Dent. 2016, 36, 807-815. [CrossRef]

14. Zeltner, M.; Jung, R.E.; Hämmerle, C.H.; Hüsler, J.; Thoma, D.S. Randomized controlled clinical study comparing a volume-stable collagen matrix to autogenous connective tissue grafts for soft tissue augmentation at implant sites: Linear volumetric soft tissue changes up to 3 months. J. Clin. Periodontol. 2017, 44, 446-453. [CrossRef] [PubMed]

15. Caballe-Serrano, J.; Zhang, S.; Ferrantino, L.; Simion, M.; Chappuis, V.; Bosshardt, D.D. Tissue Response to a Porous Collagen Matrix Used for Soft Tissue Augmentation. Material 2019, 12, 3721. [CrossRef] [PubMed]

16. Abdel-Galil, K.; Loukota, R. Fractures of the mandibular condyle: Evidence base and current concepts of management. Br. J. Oral Maxillofac. Surg. 2010, 48, 520-526. [CrossRef]

17. Imber, J.C.; Bosshardt, D.D.; Stähli, A.; Saulacic, N.; Deschner, J.; Sculean, A. Pre-clinical evaluation of the effect of a volume-stable collagen matrix on periodontal regeneration in two-wall intrabony defects. J. Clin. Periodontol. 2021, 48, 560-569. [CrossRef] [PubMed]

18. Chappuis, V.; Shahim, K.; Buser, R.; Koller, E.; Joda, T.; Reyes, M.; Buser, D. Novel collagen matrix to increase tissue thickness simultaneous with guided bone regeneration and implant placement in esthetic implant sites: A feasibility study. Int. J. Periodontics Restor. Dent. 2018, 38, 575-582. [CrossRef] [PubMed]

19. Erdfelder, E.; Faul, F.; Buchner, A. GPOWER: A general power analysis program. Behav. Res. Methods Instrum. Comput. 1996, 28, 1-11. [CrossRef]

20. Schaller, B.; Fujioka-Kobayashi, M.; Zihlmann, C.; Schuler, V.C.; Katagiri, H.; Lang, N.P.; Saulacic, N. Effects of additional collagen in biphasic calcium phosphates: A study in a rabbit calvaria. Clin. Oral Investig. 2020, 24, 3093-3103. [CrossRef]

21. Saulacic, N.; Fujioka-Kobayashi, M.; Kimura, Y.; Bracher, A.I.; Zihlmann, C.; Lang, N.P. The effect of synthetic bone graft substitutes on bone formation in rabbit calvarial defects. J. Mater. Sci. Mater. Med. 2021, 32, 14. [CrossRef]

22. Bax, D.V.; Davidenko, N.; Hamaia, S.W.; Farndale, R.W.; Best, S.M.; Cameron, R.E. Impact of UV- and carbodiimide-based crosslinking on the integrin-binding properties of collagen-based materials. Acta Biomater. 2019, 100, 280-291. [CrossRef] [PubMed]

23. Watson, S.; Berlanga, O.; Best, D.; Frampton, J. Update on collagen receptor interactions in platelets: Is the two-state model still valid? Platelets 2000, 11, 252-258. [PubMed]

24. El-Jawhari, J.; Moisley, K.; Jones, E.; Giannoudis, P. A crosslinked collagen membrane versus a non-crosslinked bilayer collagen membrane for supporting osteogenic functions of human bone marrow-multipotent stromal cells. ECells Mater. J. 2019, 37, 292-309. [CrossRef] [PubMed]

25. Delgado-Ruiz, R.A.; Calvo-Guirado, J.L.; Romanos, G.E. Critical size defects for bone regeneration experiments in rabbit calvariae: Systematic review and quality evaluation using ARRIVE guidelines. Clin. Oral Implants Res. 2015, 26, 915-930. [CrossRef]

26. Thoma, D.S.; Hämmerle, C.H.; Cochran, D.L.; Jones, A.A.; Görlach, C.; Uebersax, L.; Mathes, S.; Graf-Hausner, U.; Jung, R.E. Soft tissue volume augmentation by the use of collagen-based matrices in the dog mandible-A histological analysis. J. Clin. Periodontol. 2011, 38, 1063-1070. [CrossRef] [PubMed]

27. Bornstein, M.M.; Bosshardt, D.; Buser, D. Effect of two different bioabsorbable collagen membranes on guided bone regeneration: A comparative histomorphometric study in the dog mandible. J. Periodontol. 2007, 78, 1943-1953. [CrossRef]

28. Tal, H.; Kozlovsky, A.; Artzi, Z.; Nemcovsky, C.E.; Moses, O. Cross-linked and non-cross-linked collagen barrier membranes disintegrate following surgical exposure to the oral environment: A histological study in the cat. Clin. Oral Implants Res. 2008, 19, 760-766. [CrossRef]

29. Delgado, L.M.; Bayon, Y.; Pandit, A.; Zeugolis, D.I. To cross-link or not to cross-link? Cross-linking associated foreign body response of collagen-based devices. Tissue Eng. Part B Rev. 2015, 21, 298-313. [CrossRef]

30. Spiller, K.L.; Anfang, R.R.; Spiller, K.J.; Ng, J.; Nakazawa, K.R.; Daulton, J.W.; Vunjak-Novakovic, G. The role of macrophage phenotype in vascularization of tissue engineering scaffolds. Biomaterials 2014, 35, 4477-4488. [CrossRef]

31. Alibardi, L. Immunocalization of telomerase in cells of lizard tail after amputation suggests cell activation for tail regeneration. Tissue Cell 2016, 48, 63-71. [CrossRef]

32. Selders, G.S.; Fetz, A.E.; Radic, M.Z.; Bowlin, G.L. An overview of the role of neutrophils in innate immunity, inflammation and host-biomaterial integration. Regen. Biomater. 2017, 4, 55-68. [CrossRef] [PubMed]

33. Ye, Q.; Harmsen, M.C.; van Luyn, M.J.; Bank, R.A. The relationship between collagen scaffold cross-linking agents and neutrophils in the foreign body reaction. Biomaterials 2010, 31, 9192-9201. [CrossRef] [PubMed]

34. Bohner, M. Resorbable biomaterials as bone graft substitutes. Mater. Today 2010, 13, 24-30. [CrossRef] 